Int. J. Curr. Res. Med. Sci. (2016). 2(9): 1-7

\section{International Journal of Current Research in Medical Sciences}

ISSN: 2454-5716

WWw.ijcrims.com

Volume 2, Issue 9 -2016

\title{
A study of serum visfatin in South Indian women with polycystic ovary syndrome
}

\author{
"Kandasamy. $\mathbf{S}^{1}$, Inmozhisivagamasundari. $\mathbf{R}^{2}$, Bupathy. $\mathbf{A}^{3}$, Sethupathy. $\mathbf{S}^{4}$ \\ ${ }^{1}$ Department of Biochemistry, Jawaharlal Institute of Post Graduate Medical Education \& Research, \\ Puducherry - 605006, India. \\ ${ }^{2,4}$ Division of Biochemistry, Rajamuthaiah Medical College and Hospital, Annamalai University, \\ Tamilnadu - 603002, India. \\ ${ }^{3}$ Indira Gandhi Medical College \& Research Institute, Puducherry - 605009, India. \\ *Corresponding author: drsksamybio@gmail.com
}

\begin{abstract}
Background: Polycystic ovary syndrome [PCOS] is a common and complex heterogeneous endocrine disorder in women of reproductive age and linked to insulin resistance and obesity. Visfatin, a protein secreted by adipose tissue, is suggested to play a role in pathogenesis of insulin resistance. In view of high prevalence of obesity and type 2 diabetes mellitus in India, the aim of study this to evaluate the serum level of visfatin between PCOS patients and control subjects, and to assess the possible correlations of visfatin to insulin resistance and BMI.

Materials and methods: The study group consisted of 104 women with PCOS and 95 healthy women. Serum visfatin levels were estimated by ELISA and insulin resistance was evaluated by using Homeostasis Model Assessment of Insulin Resistance [HOMA - IR]. Data was collected and analyzed by suitable statistical methods.

Result : Serum visfatin levels were significantly increased in women with PCOS $[56.6 \pm 8.2 \mathrm{pg} / \mathrm{ml}]$ than healthy control subjects $[45.5 \pm 5.3 \mathrm{pg} / \mathrm{ml}, \mathrm{P}<0.01]$ and also serum visfatin was positively correlated with insulin resistance $[\mathrm{P}<0.01]$ and $\mathrm{BMI}[<0.05]$

Conclusion : Our results indicate that South Indian women with PCOS exhibit higher visfatin levels and elevated insulin resistance, which suggest that visfatin could be a potential biomarker for PCOS.
\end{abstract}

Keywords: Polycystic ovary syndrome, visfatin, Insulin Resistance, Obesity.

\section{Introduction}

Polycystic ovary syndrome [PCOS] is a common and complex heterogeneous endocrine disorder in women of reproductive age with a prevalence of approximately $5-10 \%$ worldwide and uncertain etiology $^{[1]}$ PCOS has been associated with hyperandrogenemia, obesity, insulin resistance, type 2 diabetes mellitus, dyslipidemia and cardiovascular disease. ${ }^{[2]}$ Insulin resistance and its resultant compensatory hyperinsulinemia play a major role in the development of sings, symptoms and related complications that are associated with $\operatorname{PCOS}^{[3]}$ The prevalence of obesity in clinical series with PCOS ranges from 30 to 75 percentage $^{[4]}$. Patients with PCOS show metabolic abnormalities combined with a more android type adiposity than normal subjects with similar BMI ${ }^{[5]}$ 
Int. J. Curr. Res. Med. Sci. (2016). 2(9): 1-7

The difference in fat distribution in women with PCOS may result in changed adipose tissue function and adipokines levels. ${ }^{[6]}$ The presence of obesity can also magnify insulin resistance.

Visfatin previously known as pre-B cell colony enhancing factor [PBEF], 52k Dalton protein expressed in a variety of tissues, including adiposities, lymphocytes, bone marrow, liver and muscle $^{[7]}$. Visfatin activate its target cells by binding to the insulin receptor, at a site distinct from insulin and to exert a variety of insulinmimetic effects under physiological condition including enhancing glucose uptake in adipose tissue and muscle, suppressing the release of glucose in hepatocytes and increasing the synthesis and accumulation of triglycerides ${ }^{[7]}$. It is now believed that visfatin action can be endocrine, paracrine and autocrine as well. These autocrine effects of visfatin may play an important role in regulating insulin sensitivity in the liver ${ }^{[8]}$. Visfatin was also soon recognized as the formerly described Nicotimide Phophoribosyltransferase[Nampt], the rate limiting enzyme in NAD biosynthesis. The plasma visfatin levels in IR-related disease including obesity and type 2 diabetes mellitus are controversial ${ }^{[9]}$. Some studies showed that the increased levels of visfatin in PCOS patients when compared with control subjects, but there are studies indicated that there was no difference between PCOS patients and control subjects ${ }^{[10]}$. On the basis of these observations the present study was designed to measure serum visfatin levels in south Indian women with PCOS and also to assess possible correlation between visfatin and insulin resistance and BMI.

\section{Materials and Methods}

One hundred and four patients with PCOS aged between 20 to 35 years were recruited from outpatient department of Obstetrics and Gynecology, Jawaharlal Institute of Post Graduate Medical Education and Research (JIPMER) Puducherry, India. The control group consisted of ninety five healthy volunteer females with regular menstrual cycles aged between 20 to 35 years. The diagnosis of PCOS was made according to the ESHRE/ASRM-sponsored PCOS consensus workshop group guidelines.
The study was approved by Institute Research Council Board and followed by Human Ethical Committee, JIPMER, and Puducherry, India. The written informed consent was obtained from patients and controls.

Patients with diabetes mellitus, thyroid dysfunctions, Cushing's syndrome, congenital adrenal hyperplasia, hyperprolactinemia, androgen secreting tumor, renal and liver dysfunction were excluded from the study by specific laboratory tests. Subjects with medication like ovulation induction agents, antiandrogens, antidiabetic, antiobesity, hormonal drugs and current or previous use of OC within last 6 months, smoking and alcohol intake were also excluded from the study.

All 104 PCOS patients and 95 healthy control underwent full physical examination and anthropometric measurements including weight, height and, waist and hip circumferences and were asked to complete a general questionnaire. Weight was measured with the subjects wearing right clothing without shoes, and height was measured using a stadiometer. Body Mass Index (BMI) was calculated by using the formula: weight $(\mathrm{Kg}) /$ height (meters). Waist circumferences (WC) were measured with the patients standing at a point mid way between lower costal margin, and ileac crest in the midauxiliary line. Hip circumferences were measured at the widest point over the buttocks. The presence and extent of hirsutism was quantified using the Ferrinman - Gallwey (F-G) score.

After overnight fasting, venous blood sample was obtained between 08.00 am and $08.30 \mathrm{am}$, on the $2^{\text {nd }}$ day of spontaneous progesterone (metroxy progesterone acetate $10 \mathrm{mg} /$ day for 7 days) induced withdrawal bleeding for (to carry out the study during the follicular phase we had to induce the menstruation in PCOS women because they were having irregular menstrual cycles) estimation of hormones, IR marker indices and visfatin levels. The plasma glucose was determined by glucose oxidase-peroxidase, end point method using a commercial kit (Agape diagnostic, India) using clinical chemistry Auto analyzer (Beckman Coulter AU680, Japan). Serum LH, FSH, insulin were determined by two- 
Int. J. Curr. Res. Med. Sci. (2016). 2(9): 1-7

site sandwich immunoassay of Chemiluminiscence method (Siemens Advia Centaur CP analyzer, Japan). Serum Testosterone, Androstenodiane, Progesterone, Estradiol, DHEAS were analyzed by competitive immunoassay of Chemiluminiscence method (Siemens Advia Centaur CP analyzer, Japan). The SHBG was measured by competitive immunoassay of Chemiluminiscence method by Siemens Advia Centaur CP analyzer. Serum visfatin was detected by ELISA kit (BI .Biotech, India) by ELISA reader (Lab- System,Finlamd). IR was determined by Homeostasis Model Assessment for insulin resistance (HOMA-IR) = Fasting glucose $(\mathrm{mg} / \mathrm{dl}) \quad \mathrm{x}$ fasting insulin $(\mu \mathrm{IU} / \mathrm{ml}) / 405$.

Statistical Analysis: All the statistical analysis were carried out using SPSS (Chicago, IL, USA) software version 16.0 for Microsoft windows. All data were presented as mean \pm standard deviation.
The paired ' $t$ ' test was used to compare the parameters of control and cases. Pearson's correlation test was used to assess the association between the parameters in PCOS patients. Statistical significance was considered as $\mathrm{P}<0.05$.

\section{Results}

The clinical and hormonal data of women with PCOS and controls are shown in table -1 . There was no significant difference in age but BMI, F-G score, LH, total Testosterone androstenedione were significantly higher in women with PCOS than controls $[p<0.01]$ and similarly WHR, LH / FSH ratio and progesterone, DHEAS were also significantly higher in women with PCOS than healthy controls $[p<0.05]$. On the other hand, patients with PCOS had significantly lower levels of FSH, estradiol and SHBG than controls $[\mathrm{P}<0.05]$.

Table - 1 Clinical features, Hormonal profiles in women with polycystic ovary syndrome and healthy controls.

\begin{tabular}{|l|c|c|}
\hline \multicolumn{1}{|c|}{ Variables } & Control $(\mathbf{n}=\mathbf{9 5})$ & PCOS (n = 104) \\
\hline Age $($ years $)$ & $27 \pm 4$ & $27.33 \pm 3.30 \mathrm{NS}$ \\
\hline Weight $(\mathrm{Kg})$ & $57 \pm 12$ & $68 \pm 4^{* *}$ \\
\hline Height $(\mathrm{Cm})$ & $1.59 \pm 0.05$ & $1.58 \pm 3.38 \mathrm{NS}$ \\
\hline BMI $\left(\mathrm{Kg} / \mathrm{m}^{2}\right)$ & $22.08 \pm 1.75$ & $27.39 \pm 1.45^{* *}$ \\
\hline Waist circumference $(\mathrm{Cm})$ & $75 \pm 4$ & $89 \pm 3^{*}$ \\
\hline Hip circumference $(\mathrm{Cm})$ & $91 \pm 5$ & $104 \pm 4^{*}$ \\
\hline Waist-hip ratio & $0.82 \pm 0.02$ & $0.85 \pm 0.01^{*}$ \\
\hline F-G Score $(>8)$ & $3.8 \pm 1.2$ & $10.2 \pm 1.6^{* *}$ \\
\hline LH $(\mu \mathrm{IU} / \mathrm{ml})$ & $5.98 \pm 1.03$ & $13.10 \pm 7.00^{* *}$ \\
\hline FSH $(\mu \mathrm{IU} / \mathrm{ml})$ & $5.74 \pm 1.16$ & $4.61 \pm 1.85^{*}$ \\
\hline LH / FSH & $1.05 \pm 0.11$ & $2.83 \pm 0.76^{*}$ \\
\hline TT $(\mathrm{ng} / \mathrm{dl})$ & $36.60 \pm 8.15$ & $63.98 \pm 16.65^{* *}$ \\
\hline Androstenedione $(\mathrm{ng} / \mathrm{dl})$ & $1.47 \pm 0.45$ & $3.64 \pm 0.87 * *$ \\
\hline Progesterone $(\mathrm{ng} / \mathrm{dl})$ & $0.45 \pm 0.40$ & $0.61 \pm 0.39^{*}$ \\
\hline Estradiol $(\mathrm{pg} / \mathrm{ml})$ & $58.92 \pm 17.21$ & $39.03 \pm 11.51^{*}$ \\
\hline SHBG $(\mathrm{nmol} / \mathrm{L})$ & $62.39 \pm 8.35$ & $42.98 \pm 11.44^{*}$ \\
\hline DHEAS $(\mu \mathrm{g} / \mathrm{dl})$ & $173.12 \pm 44.72$ & $262.64 \pm 72.33^{* *}$ \\
\hline Values are shown in mean \pm standard deviation & \\
\hline$* \mathrm{p}<0.05$ and $* * \mathrm{p}<0.01$ & & \\
NS $=$ Not significant & & \\
\hline
\end{tabular}


Int. J. Curr. Res. Med. Sci. (2016). 2(9): 1-7

The insulin resistance indices, serum visfatin levels in women with PCOS and control are listed in table -2 . The fasting plasma glucose and serum visfatin levels were significantly increased in PCOS than controls group [p<0.05]. The fasting serum insulin and HOMA - IR were also significantly increased in PCOS patients than control $[\mathrm{p}<0.01]$. The QUICKI was significantly lowered in PCOS patients than in control groups $[\mathrm{p}<0.05]$.

Table: 2 Insulin resistance indices, serum visfatin levels in women with PCOS and healthy controls.

\begin{tabular}{|l|c|c|}
\hline \multicolumn{1}{|c|}{ Variables } & Control $(\mathbf{n = 9 5})$ & PCOS(n=104) \\
\hline Fasting Glucose $(\mathrm{mg} / \mathrm{dl})$ & $83.76 \pm 6.67$ & $106.64 \pm 12.56^{*}$ \\
\hline Fasting insulin $(\mu \mathrm{IU} / \mathrm{ml})$ & $14.27 \pm 2.92$ & $35.61 \pm 5.31^{* *}$ \\
\hline HOMA - IR & $2.92 \pm 0.53$ & $9.49 \pm 2.36^{* *}$ \\
\hline QUICKI & $0.33 \pm 0.09$ & $0.28 \pm 0.09 *$ \\
\hline Visfatin $(\mathrm{pg} / \mathrm{ml})$ & $45.5 \pm 5.3$ & $56.6 \pm 8.2^{*}$ \\
\hline
\end{tabular}

Values are shown in mean \pm standard deviation

$* \mathrm{p}<0.05$ and $* * \mathrm{p}<0.01$ compared to controls

The correlation between serum levels and BMI and insulin resistance (HOMA-IR) are listed in table -3 . Serum visfatin levels were positively

correlated with BMI $(\mathrm{r}=0.328, \mathrm{p}<0.05)$ and insulin resistance $[\mathrm{r}=0.455, \mathrm{p}<0.01]$

\section{Table: 3 The Correlation between Visfatin and BMI and Insulin Resistance (HOMA-IR), in PCOS patients}

\begin{tabular}{|l|c|c|}
\hline \multirow{2}{*}{\multicolumn{1}{|c|}{ Variables }} & \multicolumn{2}{c|}{ Visfatin } \\
\cline { 2 - 3 } & r value & p value \\
\hline $\mathrm{BMI}\left(\mathrm{kg} / \mathrm{m}^{2}\right)$ & $0.328 *$ & $<0.05$ \\
\hline $\mathrm{HOMA}-\mathrm{IR}$ & $0.455^{* *}$ & $<0.01$ \\
\hline
\end{tabular}

\section{Discussion}

Polycystic ovary syndrome is a common, multifaceted endocrinopathy associated with metabolic alterations such as insulin resistance, hyperinsulinemia, dyslipidemia and obesity and there by increased risk of developing type 2 diabetes mellitus and cardiovascular disease. ${ }^{[11]}$ Interestingly, it has been shown that visfatin is released from fat cells to higher extent in PCOS compared with non-PCOS patients. ${ }^{[12,13]}$

In the present study showed that serum visfatin levels were significantly higher in women with PCOS than age matched controls. Our results are in accordance with previous studies by Yamane AD et al (2013) and others. ${ }^{\left[14,15,16,17,18,19,20,21{ }^{22]}\right.}$ In those PCOS patients were more insulin resistance than control women leading to the suggestion that visfatin could be a specific marker of insulin sensitivity, possibly contributing to the pathogenesis of PCOS .However, several recently published studies of Guducu $\mathrm{N}$ et al (2012), Lajunen TK et al S(2012) and OlszanekoGlinianowic $M$ et al (2012) did not find a difference in plasma or serum visfatin levels between patients with PCOS and control groups. ${ }^{[23,2425]}$

Evidence from a meta-analysis study of Yifan Sun et al ( 2015) shown than visfatin levels were higher in PCOS patients compared with nonPCOS controls and were not related to HOMA-IR and BMI. ${ }^{[26]}$ 
On the other hand, Seddick et al (2015) showed that visfatin levels were higher in lean PCOS patients compared to obese PCOS, obese and lean controls and these results were agreement with others studies of Pagano et al (2006) and Ramazan et al (2009) ${ }^{[27,2829]}$. The controversy of visfatin levels in different studies due to ethenic difference as it was found to Sbe higher in Asian women with PCOS than Caucasian women with PCOS. ${ }^{[30]}$

In the present study, serum visfatin was positively correlated with BMI and HOMA-IR and consistent with the recent results of Rania Sayed AE et al (2016), Junsheng Z et a 1(2013), Yamane AD et al (2013) Konowalska I et al (2007) and Dikmen E et al (2011)..$^{[31,32,33]}$ Many studies also demonstrated that visfatin displayed proinflammatory properties and modulated immune functions.$^{[34}$ 35] There is a positive correlation between the levels of visfatin and the thickness of the intima-media complex, independently of other risk factors, and this may suggest its role in the development of metabolic syndrome. ${ }^{[36]}$ Visfatin was reported to induce $\mathrm{NF}_{\mathrm{K}} \mathrm{B}$ signaling in human endothelial cells and activated MMP2/9, indicating its possible role in the pathogenesis of PCOS with its pro-inflammatory characteristics. [37]

\section{Conclusion}

Our results suggested that the elevation of serum visfatin levels in PCOS patients might be associated with obesity and insulin resistance. Serum visfatin levels thus can be used as a predictor of insulin resistance severity and also a biomarker for treatment of PCOS. Currently, the role of visfatin in PCOS patients is far from complete. Therefore, well designed studies with large sample sizes should be performed in future to find out exact role of visfatin in PCOS.

\section{Conflict of interest}

"The authors declare that they have no competing interests"

\section{References}

1. M.Pertynska - Marczewska, Evanthia Diamanti - Kandarakis, John zhang et al, Advanced glycation end products: A link between metabolic and endothelial dysfunction in PCOS. Metabolism.2015; 08:010.

2. Synder BS. The lived experiences of women diagnosed with polycystic ovary syndrome, J obstet gynecol neonatal Nurse; 2006; 35(3): 385-392.

3. Ehrmann DA - Polycystic ovary syndrome .N Eng J Med 2005; 352:1223-1236.

4. Strowitzki T, Halser b Band Demon R. Body Distribution, insulin sensitivity, ovarian dysfunction and serum lipoproteins in patients with PCOS .Gynecol endocrinol .2002;16 :4551

5. Kubato N, Terauehiy, Yamauehi T, Kubato T et al. Disruption of adiponectin causes insulin resistance and neointimal formation. $\mathrm{J}$ Bio chem. 2002; 277:25863-66.

6. Fukuhara A, Matsuda M, Nishizawa M, Segawa K et al. visfatin : a protein secreted by visceral fat that minutes the effect of insulin sciences. 2005; 307:426-430.

7. Skop V, Kontrova K, Zidek V, sajdok A et al. Autocrine effects of visfation on hepatocytes sensitivity to insulin action. Physical Rev. 2009.

8. Peiro C, Romacho T, Carraro R, SanehezFerrer CF. visfatin / PBEP/ Nampt : A new cardiovascular target? Fronties pharmacology 2010;1:135-142

9. Jing zhang, Lingling Z, Liulin I and Liangzhi $\mathrm{XU}$, plasma visfatin levels and m-RNA expression of visfatin in peripheral blood mononuclear cells and peripheral blood monocyte -derived macrophages from normal weight females with PCOS. Experimental and Therapeutic medicine. 2014; 7:1215-1220.

10. Diamanti - Kandarakis E and Dunaif. Insulin resistance and the PCOS revisited: an update on mechanism and implications. Endocrine review. 2012; 33:981-1030.

11. Rongvaux A, Shea RJ, Mulks MH, Gigot D. Pre-B-cell colony enhancing factor, whose expression is up - regulated in activated lymphocytes is a nictotinamide phosphoribosyltranferase, a cytosolic enzyme 
Int. J. Curr. Res. Med. Sci. (2016). 2(9): 1-7

involved in NAD biosynthesis. Eur J Immunol.203; 51: 484-92.

12. EKI Arner P, Ryden M, Holm C, Thorne A et al. A unique defect in the regulation of visceral fat cell lipolysis in PCOS as an early link to insulin resistance diabetes. 2002; 5:484-92.

13. Yamane AD, Kaleel AK, Shaden H,.Plasma visfatin level in women with PCOS. Int J. Phar. Sci. Rev. 2013; 22(2): 38-40.

14. Tan BK, Chen J, Digby Je, Keay et al. Increased visfatin m- RNA snd protein levels in adipose tissue and adiposities in women with PCOS: parallel increase plasma visfatin .J of Clin Endro \&meta. 2006a; 91:5022 5028.

15. Chen TF, Chen Y.L, Chen H, Lee $\mathrm{CH}$ et al. Increased plasma visfatin concentration in women with PCOS Fertility and sterility. 2007; 88: 401-405.

16. Konowalska I, Straxz Kwoski M, Niko laju KA, Adamska A, et al. Serum visfatin in relation to insulin resistance and markers of hyperandrogenism in learn and obese women with PCOS Human Repd. 2007; 22: 8241829.

17. Panidis D, Farmakiotis D, Roussod D, Katsikis I etal. Plasma visfatin levels in normal weight woman with PCOS. Euro J I Medicine - 208; 19:406-412.

18. Carmina E, Bucchien S, Mansueto P, Rini G, Ferin $\mathrm{M}$ et al. Circulating levels of adipose products and differences in fat distribution in the ovulatory and an ovulatory phenotypes of PCOS. Fertility and sterility. 2009; 91: 332 1335.

19. Ozkaya M, Cakal E, Ustum Y and Engin Ustun Y. Effect of metformin on serum visfatin levels in patients with PCOS. Fertile Steril-2010; 93: 880- 884.

20. Plati E, Kouskouni E, Malamitisi - Pucherner $\mathrm{A}$, Bcutsitou $\mathrm{M}$, et al. Visfatin and leptin levels in women with PCOS undergoing ovarian stimulation. Fertility and sterility. 2009; 94: 1451 - 1456.

21. Seow KM, Hwang JI, Wang PH, Holt et al. Expression of visfatin $m$ RNA in peripheral blood mononuclear cells is not correlated with visfatin $m$ RNA in omental adipose tissue in women with PCOS. Human Rep. 2011; 26: 2869-2873.
22. Yifan Sun Zhitong wu, Lili wei, et al. High visfatin levels in women with PCOS: evidence from meta-analysis. Gynecol Endo. 2015; early online: 1-7.

23. Guducu N, I Hsce H, Gormus U, yigiter AB et al. Serum visfatin levels in women with PCOS .Gynecol. Endocri. 2012; 28(8) 619 -23.

24. Lajunen TK, Purhonen Ak, Haapea M, Ruokonen A, ea al. Full - length visfatin levels are associated with inflammation in women with PCOS. European Journal of Clinical Investigation. 2012; 42(3): 321-8.

25. Olszanecko - Glinianowciz M, Madej P, Zdum D, Bozentowicz - Wikarek M, et al. Are plasma levels of visfatin and retinol binding protein A (RBP4) associated with body mass, metabolic and hormonal disturbances in women with PCOS? Eu.J Obst, gynecol and. Biology. 2012; 62(1) : 5561.

26. Seddick S, Elewa A, Makboul K, Bekhet M et al. Adipocytokines visfatin in patients PCOS. I nt J Adv Research in Biol Science. 2015; 2(11): 243-255.

27. Pagano C, Pilon C, Olivieri M, Mason P et al. Reduced plasma visfatin / Pre - p cell colony Enhancing factor in obesity is not related to insulin resistance in humans. J Clin Endicrin metab. 2006; 91: 365-370.

28. Ramazan Gen, Essn AKBAY, Necati MUS, Kerem Sezer LU et al. Plasma visfatin level in lean women with PCOS relation to Proinflammatory markers and insulin resistance, Gynecol End. 2009; 25 (4): 24145.

29. Chan TF, Chen YL, Lee CH, et al. Decreased plasma visfatin concentrations in women with gestational diabetes mellitus J.Soc.Gynecol. Invest. 2006; 13: 364-67.

30. Rania sayed AE, Tahany Abd ELM. Study of serum visfatin in Egyptian women with PCOS. Endocrine Abstracts. ISSN 1470.3947 (online).

31. Junsheng Z, Jian G, Shujan S, Tiansong Z et al. correlation between visfatin levels and PCOS.Journal of Biosciences and medicine. 2013; 3:2.

32. Dikmen E, Tarkan I, Cantruk Z, Certinarslam B. Plasma visfatin level in women with PCOS. Fertility and sterility .2011; 27:475479. 
Int. J. Curr. Res. Med. Sci. (2016). 2(9): 1-7

33. Fany, Meng S,Wang Y, Cao J et al. visfatin / Nampt induces EMMPRIN and MMP-P production in macrophages via the NANTMAPK-NF-kB signaling pathway. Int. J medicine. 2011; 27: 607-615.

34. Jacques C, Holzenbergrn M, Mladenovic Z, Selvat et al. Proinflammatory actions of visfatin / Nampt involve regulation of insulin signaling pathway and Nampt enzymatic activity. J B chemistry. 2012; 287:1510015108.
35. Takebayashi K, Suetsugu M, Wakabayashi S et al. Association between plasma visfatin and vascular endothelial function in patients with type 2 diabetes. Metabolism. 2007; 56:451458.

36. Adya R, Tan BK, Chen J and Randerva HS, Nuclear Factor. k B induction by visfatin in human vascular endothelial cells: its role in MMP-2/9 production and activation. Diabetes care. 2008; 37: 758-760.

\begin{tabular}{|c|l|}
\hline \multicolumn{2}{|c|}{ Access this Article in Online } \\
\hline Qund & $\begin{array}{l}\text { Website: } \\
\text { www.ijcrims.com }\end{array}$ \\
\cline { 2 - 2 } & $\begin{array}{l}\text { Subject: } \\
\text { Medical } \\
\text { Quick Response Code }\end{array}$ \\
\hline Biochemistry
\end{tabular}

\section{How to cite this article:}

Kandasamy.S, Inmozhisivagamasundari.R, Bupathy, A, Sethupathy.S. (2016). A study of serum visfatin in south Indian women with polycystic ovary syndrome. Int. J. Curr. Res. Med. Sci. 2(9): 1-7.

DOI: http://dx.doi.org/10.22192/ijcrms.2016.02.09.001 